\title{
Long non-coding RNAs in cancer invasion and metastasis
}

\author{
Xiao-han Shen ${ }^{1,2,3}$, Peng Qi ${ }^{1,2,3}$ and Xiang $\mathrm{Du}^{1,2,3}$ \\ ${ }^{1}$ Department of Pathology, Fudan University Shanghai Cancer Center, Shanghai, China; ${ }^{2}$ Department of \\ Oncology, Shanghai Medical College, Fudan University, Shanghai, China and ${ }^{3}$ Ningbo Clinical and \\ Pathological Diagnosis Center, Shanghai, China
}

\begin{abstract}
Recent large-scale transcriptome analyses have revealed that the human genome contains more than just protein-coding genes. Indeed, a large number of transcripts, including long non-coding RNAs (IncRNAs), lack protein-coding capacity, and increasing evidence suggests that IncRNAs could have a critical role in the regulation of diverse cellular processes, such as stem cell pluripotency, development, cell growth and apoptosis, and cancer invasion and/or metastasis. Furthermore, the aberrant expression of several IncRNAs is closely linked to cancer invasion and/or metastasis. Although the underlying molecular mechanisms by which IncRNAs regulate cancer invasion and/or metastasis are not clearly understood, recent studies have revealed that aberrant IncRNAs expression affects the progression of cancer. In this review, we highlight recent findings regarding the roles of IncRNAs in cancer invasion and/or metastasis.

Modern Pathology (2015) 28, 4-13; doi:10.1038/modpathol.2014.75; published online 13 June 2014
\end{abstract}

Over the last decade, advances in genome-wide analyses of the eukaryotic transcriptome have revealed that most of the human genome is transcribed. In fact, the genome was found to be more complicated than merely composed of a collection of protein-coding genes, as it shows extensive antisense, overlapping, and non-coding RNA (ncRNA) expression. ${ }^{1-3}$ Although previously considered to be transcriptional noise, recent evidence suggests that ncRNA may have a major biological role in cellular development and metabolism. ${ }^{4,5}$ One of which, the newly discovered long non-coding RNAs (lncRNAs), are defined as endogenous cellular RNAs of more than 200 nucleotides in length composed of subsets of polyadenylated and non-polyadenylated transcripts differentially accumulating in the nucleus and cytoplasm. ${ }^{5-7}$ However, lncRNAs overlapping with or interspersed between coding and noncoding transcripts have been found to lack proteincoding capacity. ${ }^{6,8}$ From a genetic point of view, lncRNAs fall into five broad categories: sense, antisense, bidirectional, intronic, and intergenic. ${ }^{4}$

Correspondence: Professor X Du, MD, PhD, Department of Pathology, Fudan University Shanghai Cancer Center or Department of Oncology, Shanghai Medical College, Fudan University or Ningbo Clinical And Pathological Diagnosis Center, 270 Dong'an Road, Shanghai 200032, P.R. China.

E-mail: dx2008cn@163.com

Received 30 October 2013; accepted 10 March 2014; published online 13 June 2014
Similar to protein-coding genes and miRNAs, lncRNAs have key roles in tumorigenesis. These molecules have been shown to have a functional role in a number of fundamental processes associated with cancer including cell cycle regulation, apoptosis, the DNA damage response, and metastasis (Table 1). A recent study has proposed six hallmarks of cancer that together form the fundamental principle of malignant transformation. The same study summarizes the conceptual basis of each hallmark as it relates to different lncRNAs. These basic hallmarks include the ability to evade growth suppressors, activate invasion and metastasis, sustain proliferative signaling, sustain replicative immortality, induce angiogenesis, and resist cell death. ${ }^{9}$

\section{One function of IncRNAs in cancer: mediating invasion and metastasis}

The capability to invade and form distant metastases involves complicated interactions and regulatory mechanisms. Therefore, improvements in morbidity and mortality will require effective treatments targeting metastatic disease. Despite the knowledge gained from more than a century of metastasis research, the molecular mechanisms are still not fully understood. It was indicated that high-grade epithelial carcinomas showed a more invasive phenotype and distant metastases, with most patients 
Table 1 Examples of lncRNAs with various modes of action in human cancers

\begin{tabular}{lclc}
\hline IncRNA & Size & Mode of action & Reference(s) \\
\hline HOTAIR & $2.2 \mathrm{~kb}$ & Chromatin remodeling & $18,19,21$ \\
MALAT1 & $\sim 7 \mathrm{~kb}$ & Protein activity modulation; sensor; scaffold & ${ }^{28-31,34,35}$ \\
LET & $\sim 2.2 \mathrm{~kb}$ & Protein activity modulation & 12 \\
H19 & $\sim 2.3 \mathrm{~kb}$ & Control of imprinting & $51-53$ \\
ANRIL & $\sim 3.9 \mathrm{~kb}$ & Chromatin remodeling & 81,82 \\
lincRNA-p21 & $\sim 3.1 \mathrm{~kb}$ & Transcriptional co-repressor & 40 \\
RN7SK & $322 \mathrm{bp}$ & Transcriptional regulation & 83,84 \\
GAS5 & $0.6-1.8 \mathrm{~kb}$ & Transcriptional repressor & 85 \\
TERRA & $\sim 2.0 \mathrm{~kb}$ & Enzyme inhibitor & 86,87 \\
aHIF & $\sim 1.6 \mathrm{~kb}$ & RNA decay & 43,88 \\
nCR-uPAR & $486 \mathrm{bp}$ & Regulation of gene expression & 89 \\
PCGEM1 & $\sim 1.6 \mathrm{~kb}$ & Regulation of gene expression & 90,91 \\
CUDR & $\sim 2.2 \mathrm{~kb}$ & Regulation of gene expression & 92 \\
& & & \\
\hline
\end{tabular}

dying from these metastases rather than from the primary tumor. ${ }^{10}$ Invasion and metastasis involves various genes and multiple steps. ${ }^{11}$ Each step in invasion and/or metastasis requires the coordinated temporal expression of genes and spatiotemporal expression of proteins. Cancer cells usually undergo morphological alterations and change their cell-cell or cell-matrix interactions. Taken together, these processes enable the cells to successfully undergo the first steps of the multistep process of invasion and metastasis.

During their transition via the lymphatic system and blood circulation, cancer cells escape immune surveillance and demonstrate anchorage-independent growth and survival. Then, the cancer cells invade their target tissues to form micrometastases and eventually form a secondary tumor. As metastatic cancers are frequently refractory to the therapeutic treatments that are effective on the primary cancers, ${ }^{12}$ it is critical to explore the knowledge of the specific regulatory mechanisms underlying tumor invasion and metastasis. In this review, we summarize the respective biological mechanisms of different lncRNAs related to cancer invasion and/or metastasis (Table 2).

\section{IncRNAs in PRC-dependent transcriptional programs}

One aspect of cancer development involves the alteration of gene expression patterns due to epigenetic changes. The polycomb group (PcG) proteins function in multiprotein complexes referred to as polycomb repressive complexes (PRCs), which repress gene expression via chromatin modification. PcG proteins bind to and repress the promoters of genes that encode proteins with key roles in cell fate determination and embryonic development. In cancer, PcG target genes are frequently epigenetically silenced by DNA methylation, ${ }^{13}$ and this silencing may be due to the high level of PcG proteins in cancer. $^{14}$

\section{HOTAIR and PCAT-1-PRC2 pathway}

Long intergenic ncRNAs (lincRNAs) are a class of pervasively transcribed genes that can serve as the interface between DNA and chromatin-modification complexes. ${ }^{15,16}$ Certain lincRNAs tether PRCs to nearby genes in cis, for example, in developmental dosage compensation and imprinting. ${ }^{17}$ The lncRNA HOTAIR is the first example of a lincRNA that regulates genes at a distance. HOTAIR, expressed from the developmental HOXC locus located on chromosome 12q13.13, binds to the PRC2 complex and targets the complex to HOXD genes located on a different chromosome, resulting in the cross-regulation of $H O X$ genes for proper positional identity. ${ }^{15,18}$ Gupta et $a l^{19}$ recently revealed an important role for HOTAIR in breast cancer metastasis. HOTAIR is highly induced in metastatic breast cancer, and a high level of HOTAIR expression in primary breast tumors is a powerful predictor of eventual metastasis and mortality. ${ }^{19,20}$ HOTAIR overexpression induced the genome-wide localization of the PRC2 subunit enhancer of zeste homolog 2 (EZH2) to many genes, leading to altered histone H3 lysine 27 methylation and the downregulation of multiple metastasis suppressor genes, including HOXD10, JAM2, and PCDH10 (Figure 1). ${ }^{19-22}$ Conversely, the loss of HOTAIR can inhibit cancer invasiveness, particularly in cells that possess excessive PRC2 activity. ${ }^{21}$ Kogo et al ${ }^{18}$ also suggested that HOTAIR expression is associated with the genome-wide reprogramming of PRC2 function in both breast cancer and colorectal carcinoma (CRC), whereby the upregulation of this lncRNA may be a critical element for metastatic progression.

Similar regulatory mechanisms may occur in prostate cancer-associated ncRNA transcripts-1 (PCAT1), another lncRNA that was first found to be highly expressed in prostate cancer. PCAT-1 resides in the 8q24 'gene desert' locus, within the vicinity of wellstudied SNPs associated with prostate cancer risk and approximately $725 \mathrm{~kb}$ upstream of the $c-M Y C$ oncogene, suggesting that this locus may be linked 
Table 2 Examples of potential lncRNAs associated with cancer invasion and/or metastasis

\begin{tabular}{|c|c|c|c|c|c|}
\hline Туре & $\ln c R N A$ & Genomic location & Cancer types & $\begin{array}{l}\text { Function in cancer invasion } \\
\text { and/or metastasis }\end{array}$ & References \\
\hline \multirow[t]{3}{*}{$\begin{array}{l}\text { PRC pathway- } \\
\text { related lncRNAs }\end{array}$} & HOTAIR & $\begin{array}{l}\text { Intergenic, Hox C locus, } \\
12 q 13.13\end{array}$ & $\begin{array}{l}\text { Breast, liver, colon, } \\
\text { stomach, nasopharynx, } \\
\text { esophagus, skin }\end{array}$ & $\begin{array}{l}\text { Gene silencing via } \\
\text { interaction with PRC2 }\end{array}$ & $18-21,70-73$ \\
\hline & PCAT-1 & $\begin{array}{l}\text { Intergenic, } 8 \mathrm{q} 24 \text { locus, } \\
725 \mathrm{~kb} \text { upstream of } c-M Y C\end{array}$ & Prostate, colon & $\begin{array}{l}\text { Gene silencing via } \\
\text { interaction with PRC2 }\end{array}$ & $24-26$ \\
\hline & MALAT1 & Intergenic, Chr11q13 & $\begin{array}{l}\text { Breast, lung, uterus, } \\
\text { pancreas, colon, } \\
\text { prostate, liver, } \\
\text { osteosarcoma }\end{array}$ & $\begin{array}{l}\text { Interaction with PRC1 } \\
\text { leading to relocalization of } \\
\text { metastasis-associated } \\
\text { proteins }\end{array}$ & $28-31,34,35$ \\
\hline \multirow{5}{*}{$\begin{array}{l}\text { Signaling } \\
\text { transduction } \\
\text { pathway-related } \\
\text { lncRNAs }\end{array}$} & MALAT1 & Intergenic, Chr11q13 & Bladder & $\begin{array}{l}\text { Promotion of EMT by } \\
\text { activating the Wnt/ } \beta \text {-catenin } \\
\text { pathway }\end{array}$ & 49 \\
\hline & H19 & $\begin{array}{l}\text { Imprinted at the Igf2 locus } \\
\text { in Chr11, 11p } 15.5\end{array}$ & Bladder, liver & $\begin{array}{l}\text { Promotion of EMT by } \\
\text { activating the Wnt/ } \beta \text {-catenin } \\
\text { pathway }\end{array}$ & 53 \\
\hline & CCAT2 & Unknown, 8q24 & Colon & $\begin{array}{l}\text { Activation of the Wnt } \\
\text { signaling pathway }\end{array}$ & 54 \\
\hline & $\begin{array}{l}\text { LET (NPTN intronic } \\
\text { transcript 1) }\end{array}$ & Intronic, 15q24.1 & Liver, colon, lung & $\begin{array}{l}\text { A tumor suppressor in the } \\
\text { HIF- } 1 \alpha \text { pathway }\end{array}$ & 42 \\
\hline & $\begin{array}{l}\text { Intronic lncRNAs } \\
(P P P 3 C B, M A P 3 K 14 \\
\text { and } D A P K 1 \text { loci })\end{array}$ & $\begin{array}{l}\text { Intronic, } P P P 3 C B \text {, } \\
M A P 3 K 14 \text { and } D A P K 1 \text { loci: } \\
\text { 10q22.2, 17q21 and } \\
\text { 9q21.33 }\end{array}$ & Pancreas & $\begin{array}{l}\text { Associated with the MAPK } \\
\text { pathway }\end{array}$ & 64 \\
\hline
\end{tabular}

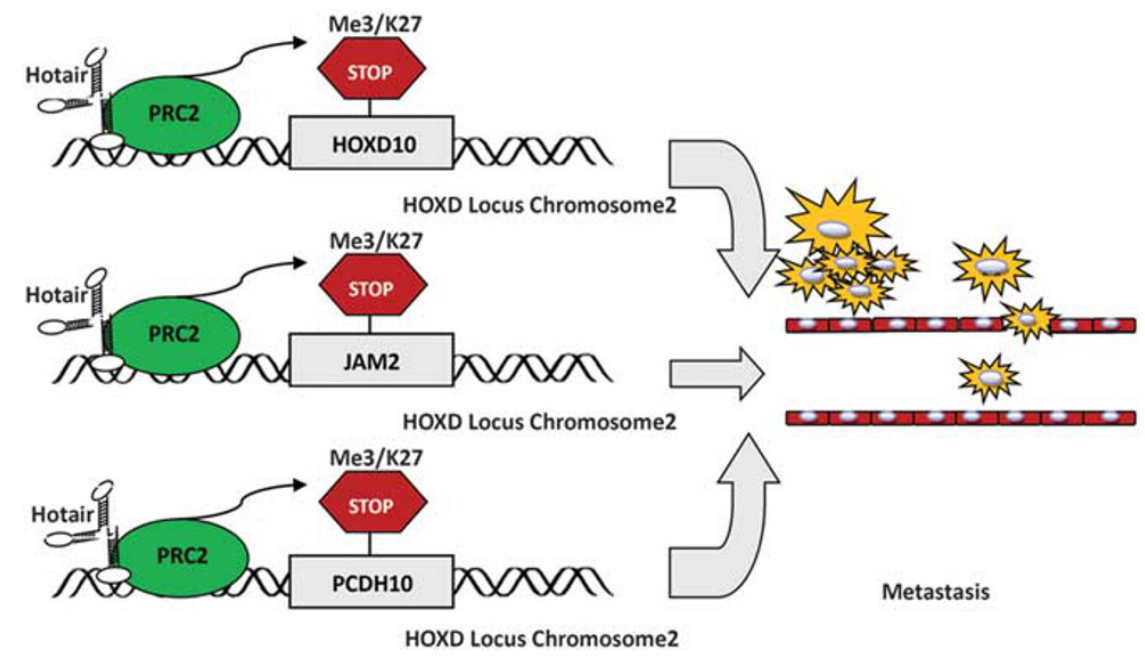

Figure 1 Proposed metastatic mechanism of HOTAIR in cancer.

to additional aspects of cancer biology. ${ }^{23}$ Prensner et $a l^{24}$ recently showed that PCAT-1 is upregulated in a subset of metastatic and high-grade localized cancers and can promote cancer cell proliferation by repressing the PRC2 complex. It was suggested that PCAT-1 might also be coordinated with the oncoprotein EZH2, which encodes a core PRC2 protein that contributes to the metastatic phenotype. Knockdown of EZH2 causes the dramatic upregulation of PCAT-1 expression, ${ }^{24}$ and PCAT-1 overexpression leads to increased cell proliferation in vitro and is associated with metastasis in prostate cancer. The PCAT-1 upregulation observed in prostate cancer may represent an adaptive cellular mechanism for overcoming controlled proliferation and promoting metastasis. ${ }^{25,26}$ Furthermore, a recent report has demonstrated that PCAT-1 is similarly upregulated in CRC and is highly related to CRC metastasis. ${ }^{25}$ However, further investigation is still required to illustrate the regulatory mechanism of PCAT-1.

\section{MALAT1-PRC1 pathway}

MALAT1 (metastasis-associated lung adenocarcinoma transcript 1), also later referred to as NEAT2 (nuclear- 
enriched abundant transcript 2), is a prognostic marker for metastasis and patient survival in non-small cell lung cancer. ${ }^{9,27}$ This ncRNA is extremely abundant in many human cell types and is highly conserved across several species, underscoring its functional importance. MALAT1 has been linked to a variety of cancers of the breast, liver, and nasopharynx. ${ }^{28-30}$

The molecular mechanism of MALAT1 action is currently under debate. Previous studies have identified MALAT1 as a regulator of the alternative splicing (AS) of a subset of genes. ${ }^{31}$ Other studies have revealed that MALAT1 is an active player in lung cancer metastasis and have found that the genetic regulation of metastasis-associated genes, rather than AS, is the critical MALAT1 mechanism in metastasis. ${ }^{32,33}$ MALAT1 was found to interact with the demethylated form of CBX4 (chromobox homolog 4), also referred to as polycomb 2 (Pc2), a component of the polycomb repressive complex 1 (PRC1). E2F1 is a transcription factor that has a crucial role in cell cycle control and the action of tumor suppressor proteins. Binding of MALAT1 to unmethylated Pc2 promotes E2F1 SUMOylation, leading to the relocalization of growth control proteins between polycomb bodies and interchromatin granules, which are areas of genetic silencing and active gene expression, respectively. MALAT1 resides in these subnuclear structures and functions as an activator of gene expression, potentially by mediating the assembly of coactivator complexes. ${ }^{32}$ One study identified a set of genes that might act to promote lung cancer metastasis, reporting that the expression of these genes depends on MALAT1. ${ }^{34-37}$ These MALAT1 target genes were either associated with metastasis or represented critical regulators of metastasis establishment, and were strongly reduced by the loss of MALAT1. ${ }^{34}$ These reports support the hypothesis that MALAT1 is an activator of metastasis and affects metastatic processes.

In summary, HOTAIR and MALAT1 regulate a broad subset of genes involved in cancer cell invasion and metastasis. On the one hand, these two lncRNAs are part of the 'metastatic signature' of gene expression; on the other hand, they contribute to shaping this signature. Regardless, further studies are necessary to elucidate the mechanism of PCAT-1 regulation. Taken together, these findings reveal an lncRNA-PRC pathway for cancer invasion and metastasis and suggest that lncRNAs are not only prognostic biomarkers for metastasis development but may also be major players in disease progression by regulating metastatic gene expression programs.

\section{IncRNAs in signal transduction pathways}

Cancer often arises when normal cellular growth goes awry due to defects in critical signal transduction pathways. ${ }^{38,39}$ Although lncRNAs have recently emerged as novel biomarkers in cancer development and progression, many of them have been found to be associated with fundamental biological processes and signaling networks (ie, the p53 pathway). Huarte et $a l^{40}$ have demonstrated that numerous lncRNAs are key constituents in the p53-dependent transcriptional pathway. ${ }^{41}$ However, the means by which lncRNAs function in cancer invasion and/or metastasis via different signal transduction pathways is still unclear and must be further investigated and clarified. Here, we summarize the particular lncRNAs that have been studied with regard to this aspect.

\section{LET-HIF-1 $\alpha$ pathway}

LncRNA-low expression in tumor (lncRNA-LET), also known as NPTN intronic transcript 1, is significantly underexpressed in hepatocellular carcinoma (HCC), CRC, and squamous cell lung carcinoma tissues compared with its expression in peritumoral tissue. Furthermore, a lower lncRNALET level was found to be associated with tumor metastasis and determined to have tumor suppressor activity. ${ }^{42}$ Hypoxic microenvironments have a critical role in the metastasis of various cancers, ${ }^{12,43}$ and it has been demonstrated that a hypoxic microenvironment suppresses lncRNA-LET through histone deacetylase 3 (HDAC3) activation, resulting in reduced histone $\mathrm{H} 3$ and $\mathrm{H} 4$ acetylation levels in the lncRNA-LET promoter region. NF90 is a doublestranded RNA-binding protein implicated in the translational control of many target mRNAs, including hypoxia-inducible factor 1 alpha (HIF$1 \alpha$ ) subunit and cell division cycle 42 (CDC42) (44,45 $^{4}$ The lncRNA-LET transcript was found to associate with NF90 to promote NF90 protein ubiquitination and subsequent degradation, and the downregulation of lncRNA-LET was found to be a key step in the stabilization of nuclear factor 90 protein via the ubiquitin-proteasome pathway. The association between lncRNA-LET and NF90 indirectly regulates the protein levels of HIF- $1 \alpha$ and CDC42, and the HIF-1 $\alpha /$ HDAC3/lncRNA-LET/NF90 signaling pathway might provide a positive feedback loop that augments the HIF- $1 \alpha$ response, leading to hypoxiainduced cancer cell invasion and tumor metastasis (Figure 2). ${ }^{12}$ These results indicate that lncRNA-LET acts as a tumor suppressor and may promote HCC metastasis when downregulated, suggesting that it may be an important target for tumor therapy.

\section{MALAT1, H19 and CCAT2-Wnt/ $\beta$-catenin pathway}

Recent studies are helping to unravel the association between EMT and lncRNA. EMT is a key step toward cancer metastasis. E-cadherin (CDH1) is a critical cell-to-cell adhesion molecule and aids in the assembly of epithelial cell layers; therefore, increased CDH1 expression inhibits invasion and metastasis formation. Accordingly, the loss of E-cadherin expression 


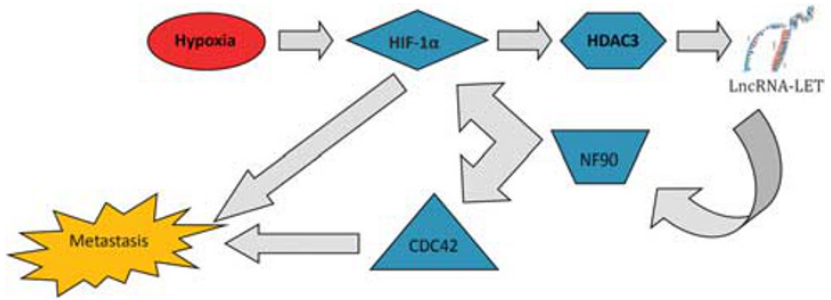

Figure 2 Proposed metastatic mechanism of IncRNA-LET in cancer.

is a hallmark of the EMT process and is likely required for enhanced tumor cell migration. ${ }^{46}$ The Wnt signaling pathway has a particularly tight link with EMT ${ }^{47}$ Canonical Wnt signaling is activated on the binding of Wnt ligands to Frizzled (Fzd)/LDLrelated protein coreceptor complexes, which leads to the activation of Fzd and the nuclear translocation of $\beta$-catenin. The nuclear translocation of $\beta$-catenin in turn activates the expression of Slug, which triggers EMT and a proinvasive gene expression profile. ${ }^{47,48}$

As mentioned above, MALAT1 functions as an active player in cancer metastasis by interacting with the demethylated form of Pc2, a component of PRC1, thereby promoting E2F1 SUMOylation and leading to relocalization of growth control proteins. However, another report has suggested that MALAT1 promotes EMT by activating the Wnt/ $\beta$ catenin pathway in bladder cancer cells: the downregulation of MALAT1 resulted in a decrease in the levels of Slug, as well as ZEB1 and ZEB2 (known as transcriptional repressors of E-cadherin), and an increase in CDH1 levels, indicating that MALAT1 promotes EMT by activating Wnt signaling. ${ }^{49}$

LncRNA H19 may be involved in a similar regulatory mechanism. H19, an imprinted and maternally expressed oncofetal gene, is located on chromosome 11 p15.5 near the IGF II (encoding insulin-like growth factor II) locus. ${ }^{50} \mathrm{H} 19$ is expressed abundantly in many cancers and only marginally in nearly all normal adult tissues. ${ }^{50}$ Adriaenssens et $a l^{51}$ have suggested that H19 has a role in epithelialmesenchymal interactions and thus in morphogenesis and/or migration of epithelial cells. A previous study has shown that H19 is highly expressed in hepatic metastases from a range of human carcinomas, ${ }^{52}$ although the underlying mechanism has not been clearly shown. A recent study suggested that upregulated H19 enhances bladder cancer metastasis by associating with EZH2, resulting in Wnt/ $\beta$-catenin activation and the subsequent downregulation of $\mathrm{CDH} 1 .^{53}$

Recent research has identified another novel lncRNA-CCAT2 that maps to 8q24, is highly overexpressed in colorectal cancer, and promotes tumor growth, metastasis, and chromosomal instability. ${ }^{54}$ It has been demonstrated that MYC, miR-17-5p, and miR-20a are upregulated by CCAT2 through TCF7L2-mediated transcriptional regulation, and the physical interaction between CCAT2 and TCF7L2 results in the enhancement of Wnt signaling activity. CCAT2 is also a Wnt downstream target, which suggests the existence of a feedback loop. ${ }^{54}$

\section{Intronic IncRNAs (PPP3CB, MAP3K14, and DAPK1 loci) and MAPK pathway}

The activity of the RAS/MAPK pathway was shown to be significantly elevated in both primary and metastatic lesions, and the inhibition of RAS/MAPK signaling significantly reduced the metastatic progression of transplanted stem/progenitor cells. These findings suggest that RAS/MAPK activation could have a critical role in promoting cancer progression and metastasis. ${ }^{55}$

Some of the earliest and most universal genetic alterations observed in pancreatic cancer are activating mutations in the oncogene $K R A S .{ }^{56}$ At least $99 \%$ of pancreatic intraepithelial neoplasia lesions harbor mutations in KRAS, suggesting that its activation is an important initiating step in the carcinogenesis of most pancreatic cancers. ${ }^{57}$ Activating mutations in the KRAS gene result in a loss of the intrinsic GTPase activity of the Ras protein, and constitutive signaling occurs, even in the absence of extracellular signals. ${ }^{58}$ Activated Ras is involved in a number of signaling pathways, including the RAF/MAPK pathway, resulting in Ras-Raf-MAPK signaling. ${ }^{59,60}$

Recently, pancreatic ductal adenocarcinoma (PDAC) was studied to identify the gene expression profiles of lncRNAs correlated with pancreatic cancer and metastasis. ${ }^{61-63}$ A subset of intronic lncRNAs (PPP3CB, MAP3K14, and DAPK1 loci) expressed in pancreatic tissues was identified; the abundance of these lncRNAs was correlated with PDAC metastasis and were enriched in genes associated with the MAPK pathway. ${ }^{64,65}$ Nevertheless, further studies will be necessary to reveal the possible biological functions and molecular mechanisms of these lncRNAs in PDAC tumorigenesis and/or progression, and these intronic lncRNAs might be novel candidate biomarkers of pancreatic tumors.

The data accumulated thus far have suggested that lncRNAs may mediate cancer invasion and metastasis via different signal transduction pathways. These results advance our understanding of the role of lncRNAs as regulators of various signaling pathways and offer new avenues for therapeutic intervention against cancer progression.

\section{IncRNAs as diagnostic and prognostic markers}

Cancer is a complicated, multifactorial, multistep disease. Desirable molecular markers of malignancy are important diagnostic and prognostic tools that can aid in patient management in oncology clinics. 
Numerous molecular markers for various cancers have been discovered and validated over the last few decades, and lncRNAs may be new potential markers based on their roles in different pathways. Several lncRNAs have been suggested to be dysregulated in various cancers, such as breast cancer, colorectal cancer, HCC, prostate cancer, bladder cancer, and lung cancer (Table 2), ${ }^{18-21,23-34}$ indicating that lncRNAs may become a promising biomarker in cancer diagnosis and prognosis.

Cancer metastasis portends a poor prognosis and cannot be reliably predicted. In the setting of metastasis, patients usually have a poorer prognosis and shorter survival period, and few patients achieve a durable remission with the currently available therapies. Tumor metastasis cannot be reliably predicted based on patients' clinical manifestations, pathologic findings, or other currently available laboratory tests. Although different methods have been used to predict clinical outcomes for patients with metastasis on the basis of clinical and pathologic features, these approaches do not incorporate the more complex biological features of individual patients. ${ }^{66}$

Recent studies have shown that the metastatic capability of cancer is conferred by genetic changes that occur relatively early in tumorigenesis and that metastatic dissemination may occur continually throughout the course of primary tumor development. ${ }^{67-69}$ Therefore, it is scientifically and clinically relevant to identify metastasis-specific molecular biomarkers to predict metastasis. Numerous proteinaceous molecular markers for various cancer metastases have been discovered and validated over the last few decades, and lncRNAs are emerging as new factors that have potential roles as diagnostic and prognostic predictors via both oncogenic and tumor-suppressive pathways. For example, the increased expression of the lncRNA HOTAIR was shown to be associated with metastasis in breast cancer patients, demonstrating a unique association with patient prognosis. ${ }^{20}$ Besides, HOTAIR expression levels were found to be correlated with metastasis in colorectal cancer and many other malignant neoplasms in liver, stomach, nasopharynx, esophagus, and skin, thus becoming a predictor of tumor recurrence in patients. ${ }^{18,20,70-73}$ In addition, the inhibition of MALAT1, which is associated with metastasis and poor prognosis, might be an effective therapeutic strategy for metastatic cancer. Importantly, the inhibition of MALAT1 does not affect normal cells because this protein is not required for the viability of these cells. ${ }^{9,28,33,34}$ Recently, Wheeler et al. ${ }^{74}$ reported a novel strategy for effectively abolishing MALAT1 in vivo using antisense oligonucleotides. This result strongly supports the notion that the elimination of MALAT1 using gene therapy has an excellent potential for curing metastatic cancers. Besides non-small lung cancer, MALAT1 was also found to involve in the progression of other tumors. For example, Ren $\mathrm{S}$ et $a l^{75}$ demonstrated that siRNA targeting MALAT1 elicited delayed tumor growth and reduced metastasis of prostate cancer xenografts in castrated male nude mice, suggesting that MALAT1 may be needed to maintain prostate tumorigenicity and may serve as a potential therapeutic target for castration-resistant prostate cancer. Like HOTAIR, MALAT1 was also known to be misregulated in many other cancer metastases, including CRC and bladder cancer. ${ }^{49,76}$ HOTAIR and MALAT1 both act as oncogenic lncRNAs, whereas some other lncRNAs were found to exert tumor-suppressive roles in cancer invasion and metastasis. For instance, lncRNA-LET was discovered to be significantly underexpressed in HCC, CRC, as well as squamous cell lung carcinoma tissues compared with its expression in peritumoral tissue, and a lower lncRNA-LET level was found to be associated with tumor metastasis and determined to have tumor suppressor activity. ${ }^{42}$ Another lncRNA called lincRNA-BM742401 was downregulated in cancer, and its downregulation was associated with poor survival in gastric cancer patients. Ectopic overexpression of BM742401 inhibited metastasis-related phenotypes and decreased the concentration of extracellular MMP9, suggesting that BM742401 is also a potential lncRNA marker and therapeutic target $^{77}$ (Table 3).

One single lncRNA may indicate poor/good prognosis of various tumors, such as HOTAIR, MALAT1, and LET mentioned above. On the other hand, various lncRNAs may be over/underexpressed in one single tumor type. For example, in CRC, HOTAIR, PCAT-1, MALAT1, CCAT2 were discovered to act as oncogenes and overexpressions of these lncRNAs indicate a poor prognosis by promoting cancer metastasis. While Lower LET and ncRAN expression levels were significantly associated with poor disease outcome for CRC patients, thereby having tumor-suppressive roles in cancer ${ }^{42,78}$ (Table 3).

Overall, an understanding of the precise molecular mechanisms by which lncRNAs function in various invasive and metastatic tumors will be critical for the development of new potential strategies for early diagnosis and therapy. It is necessary to revisit established methods for targeting RNA molecules and discuss new agents and strategies of lncRNAs as biomarkers in cancer invasion and metastasis.

\section{Conclusions and perspectives}

Much progress has been made in recent years concerning the biological mechanisms of cancer invasion and/or metastasis. The idea that invasion is regulated by the developmental regulatory program known as EMT is a hot topic. Indeed, EMT processes, which are characterized by diminished epithelial and increased mesenchymal characteris- 
Table 3 lncRNAs as therapy targets for metastasis in different cancer types

\begin{tabular}{|c|c|c|c|}
\hline Cancer types & $\begin{array}{l}\text { Oncogenic lncRNAs/high-expressed } \\
\text { lncRNAs in cancer metastasis }\end{array}$ & $\begin{array}{l}\text { Tumor-supressive lncRNAs/low-expressed } \\
\text { lncRNAs in cancer metastasis }\end{array}$ & References \\
\hline Breast cancer & HOTAIR, MALAT1 & & 19,29 \\
\hline $\begin{array}{l}\text { Non-small cell lung } \\
\text { carcinoma }\end{array}$ & MALAT1, CCAT2 & LET, GAS6-AS1 & $27,33,34,42,93,94$ \\
\hline $\begin{array}{l}\text { Nasopharyngeal } \\
\text { carcinoma }\end{array}$ & HOTAIR, MALAT1 & & 28,71 \\
\hline Colorectal carcinoma & HOTAIR, PCAT-1, MALAT1, CCAT2 & LET, ncRAN & $18,25,42,54,76,78$ \\
\hline Gastric carcinoma & HOTAIR, MALAT1, HULC & BM742401, AC096655.1-002 & $30,72,77,95,96$ \\
\hline $\begin{array}{l}\text { Hepatocellular } \\
\text { carcinoma }\end{array}$ & HOTAIR, MALAT1, H19, HULC & LET, Dreh & $21,30,42,52,97,98$ \\
\hline $\begin{array}{l}\text { Esophageal squamous } \\
\text { cell carcinoma }\end{array}$ & HOTAIR, PlncRNA-1 & & 70,99 \\
\hline Prostate cancer & MALAT1, PCAT-1 & & 24,75 \\
\hline Bladder cancer & Linc-UBC1, H19, MALAT1 & & $49,53,100$ \\
\hline Melanoma & HOTAIR & & 73 \\
\hline
\end{tabular}

tics, endow epithelial cells with an enhanced migratory potential and have been implicated in many pathological processes requiring cell migration. ${ }^{79}$ EMT is a key step toward cancer metastasis: in most carcinomas, the invasion of cancer cells into the surrounding tissues involves their molecular reprogramming as part of EMT. ${ }^{9}$ In this review, we related that some lncRNAs, such as MALAT1 and H19, were found to promote EMT by activating the $\mathrm{Wnt} / \beta$-catenin pathway in bladder cancer cells. ${ }^{49,53}$ A recent study has identified the role of HOTAIR within the context of EMT and has suggested that HOTAIR inhibition could reverse the EMT process in gastric carcinoma cells. Furthermore, the expression of Snail, one of the major transcription factors regulating EMT, could be induced by HOTAIR overexpression, implying that HOTAIR could act as a potential regulator of EMT. ${ }^{80}$ It is possible that other lncRNAs could be important during EMT or could act as regulators of other EMT-related genes. In addition, it is possible that lncRNAs could be involved in the complex interplay between tumor cells and the tumor stroma or that they could also influence inflammatory cell behavior. Further investigations and studies will be required to confirm these possibilities.

In this review, we highlighted the several lncRNAs that have functional roles in cancer-associated invasive and metastatic processes. An understanding of the interrelationships between regulatory genes and gene products (including lncRNA) and how these relationships are modulated within the microenvironmental context is necessary to unravel the complex tapestry of cancer invasion and/or metastasis. Further studies are needed to identify the genetic networks and pathways that are regulated by abnormally expressing lncRNAs to fully understand the molecular basis of cancer cell invasion and metastasis, In addition, it will become essential to explore the potential utility of lncRNAs in cancer as diagnostic and prognostic markers, as well as the potential of developing lncRNA-mediated therapy.

\section{Acknowledgments}

This study was supported by National Clinical Key Discipline (2013-2015), Priority of Shanghai key discipline of medicine (2013-2015), Shanghai R\&D public service platform construction projects (12DZ2295100), National Natural Science Foundation of China (81071791), Clinical Key Discipline Fund by Ministry of Health (2010-2012) and Shanghai Science and Technology Development Fund (Basic Research Major Project, No. 10DJ1400500).

\section{Disclosure/conflict of interest}

The authors declare no conflict of interest.

\section{References}

1 Kapranov P, Willingham AT, Gingeras TR. Genomewide transcription and the implications for genomic organization. Nat Rev Genet 2007;8:413-423.

2 Khachane AN, Harrison PM. Mining mammalian transcript data for functional long non-coding RNAs. PLoS One 2010;5:e10316.

3 Guttman M, Amit I, Garber M, et al. Chromatin signature reveals over a thousand highly conserved large non-coding RNAs in mammals. Nature 2009; 458:223-227.

4 Ponting CP, Oliver PL, Reik W. Evolution and functions of long noncoding RNAs. Cell 2009;136:629-641.

5 Kapranov P, St. Laurent G, Raz T, et al. The majority of total nuclear-encoded non-ribosomal RNA in a human cell is "dark matter" un-annotated RNA. BMC Biol 2010;8:149.

6 Mercer TR, Dinger ME, Mattick JS. Long non-coding RNAs: insights into functions. Nat Rev Genet 2009; 10:155-159.

7 Birney E, Stamatoyannopoulos JA, Dutta A, et al. Identification and analysis of functional elements in $1 \%$ of the human genome by the ENCODE pilot project. Nature 2007;447:799-816. 
8 Carninci P, Kasukawa T, Katayama S, et al. The transcriptional landscape of the mammalian genome. Science 2005;309:1559-1563.

9 Gutschner T, Diederichs S. The hallmarks of cancer: a long non-coding RNA point of view. RNA Biol 2012; 9:703-719.

10 Talmadge JE, Fidler IJ. AACR centennial series: the biology of cancer metastasis: historical perspective. Cancer Res 2010;70:5649-5669.

11 Eccles SA, Welch DR. Metastasis: recent discoveries and novel treatment strategies. Lancet 2007;369: 742-757.

12 Liu Q, Liu L, Zhao Y, et al. Hypoxia induces genomic DNA demethylation through the activation of HIF-1 $\alpha$ and transcriptional upregulation of MAT2A in hepatoma cells. Mol Cancer Ther 2011;10:1113-1123.

13 Ohm JE, McGarvey KM, Yu X, et al. A stem cell-like chromatin pattern may predispose tumor suppressor genes to DNA hypermethylation and heritable silencing. Nat Genet 2007;39:237-242.

14 Sparmann A, van Lohuizen M. Polycomb silencers control cell fate, development and cancer. Nat Rev Cancer 2006;6:846-856.

15 Rinn JL, Kertesz M, Wang JK, et al. Functional demarcation of active and silent chromatin domains in human HOX loci by non-coding RNAs. Cell 2007;129:1311-1323.

16 Khalil AM, Guttman M, Huarte M, et al. Many human large intergenic noncoding RNAs associate with chromatin-modifying complexes and affect gene expression. Proc Natl Acad Sci USA 2009;106: 11667-11672.

17 Zhao J, Sun BK, Erwin JA, et al. Polycomb proteins targeted by a short repeat RNA to the mouse X-chromosome. Science 2008;322:750-756.

18 Kogo R, Shimamura T, Mimori K, et al. Long noncoding RNA HOTAIR regulates polycomb-dependent chromatin modification and is associated with poor prognosis in colorectal cancers. Cancer Res 2011;71:6320-6326.

19 Gupta RA, Shah N, Wang KC, et al. Long noncoding RNA HOTAIR reprograms chromatin state to promote cancer metastasis. Nature 2010;464:1071-1076.

20 Chisholm KM, Wan Y, Li R, et al. Detection of long non-coding RNA in archival tissue: correlation with polycomb protein expression in primary and metastatic breast carcinoma. PLoS One 2012;7:e47998.

21 Wan Y, Chang HY. HOTAIR: flight of noncoding RNAs in cancer metastasis. Cell Cycle 2010;9:3391-3392.

22 Kleer CG, Cao Q, Varambally S, et al. EZH2 is a marker of aggressive breast cancer and promotes neoplastic transformation of breast epithelial cells. Proc Natl Acad Sci USA 2003;100:11606-11611.

23 Shi X, Sun M, Liu H, et al. Long non-coding RNAs: a new frontier in the study of human diseases. Cancer Lett. 2013;339:159-166.

24 Prensner JR, Iyer MK, Balbin OA, et al. Transcriptome sequencing across a prostate cancer cohort identifies PCAT-1, an unannotated lincRNA implicated in disease progression. Nat Biotechnol 2011;29:742-749.

25 Ge XS, Chen YB, Liao XY, et al. Overexpression of long noncoding RNA PCAT-1 is a novel biomarker of poor prognosis in patients with colorectal cancer. Med Oncol 2013;30:588

26 Prensner JR, Rubin MA, Wei JT, et al. Beyond PSA: the next generation of prostate cancer biomarkers. Sci Transl Med 2012;4127rv3.
27 Ji P, Diederichs S, Wang W, et al. MALAT-1, a novel noncoding RNA, and thymosin beta4 predict metastasis and survival in early-stage non-small cell lung cancer. Oncogene 2003;22:8031-8041.

28 Xie L, Hu Z, Wang X, et al. Expression of long noncoding RNA MALAT1 gene in human nasopharyngeal carcinoma cell lines and its biological significance. Nan Fang Yi Ke Da Xue Xue Bao 2013;33: 692-697.

29 Guffanti A, Iacono M, Pelucchi P, et al. A transcriptional sketch of a primary human breast cancer by 454 deep sequencing. BMC Genomics 2009;10:163.

30 Lin R, Maeda S, Liu C, et al. A large noncoding RNA is a marker for murine hepatocellular carcinomas and a spectrum of human carcinomas. Oncogene 2007;26:851-858.

31 Tripathi V, Ellis JD, Shen Z, et al. The nuclearretained noncoding RNA MALAT1 regulates alternative splicing by modulating SR splicing factor phosphorylation. Mol Cell 2010;39:925-938.

32 Yang L, Lin C, Liu W, et al. NcRNA- and Pc2 methylation-dependent gene relocation between nuclear structures mediates gene activation programs. Cell 2011;147:773-788.

33 Schmidt LH, Spieker T, Koschmieder S, et al. The long noncoding MALAT-1 RNA indicates a poor prognosis in non-small cell lung cancer and induces migration and tumor growth. J Thorac Oncol 2011;6: 1984-1992.

34 Gutschner T, Hämmerle M, Eissmann M, et al. The noncoding RNA MALAT1 is a critical regulator of the metastasis phenotype of lung cancer cells. Cancer Res 2013;73:1180-1189.

35 Hellerbrand C, Amann T, Schlegel J, et al. The novel gene MIA2 acts as a tumour suppressor in hepatocellular carcinoma. Gut 2008;57:243-251.

$36 \mathrm{Xu} \mathrm{Y,} \mathrm{Li} \mathrm{WL,} \mathrm{Fu} \mathrm{L,} \mathrm{et} \mathrm{al.} \mathrm{Slit2/Robo1} \mathrm{signaling} \mathrm{in}$ glioma migration and invasion. Neurosci Bull 2010; 26:474-478.

37 Sekine Y, Demosky SJ, Stonik JA, et al. High-density lipoprotein induces proliferation and migration of human prostate androgen-independent cancer cells by an ABCA1-dependent mechanism. Mol Cancer Res 2010;8:1284-1294.

38 Jeremy SL, Deborah KM. Complexity in the signaling network: insights from the use of targeted inhibitors in cancer therapy. Genes Dev 2012;26:641-650.

39 Vogelstein B, Kinzler KW. Cancer genes and the pathways they control. Nat Med 2004;10:789-799.

40 Huarte M, Guttman M, Feldser D, et al. A large intergenic noncoding RNA induced by p53 mediates global gene repression in the p53 response. Cell 2010;142:409-419.

41 Antonella B, Andrea M. Long non-coding RNAs and p53 regulation. Int J Mol Sci 2012;13:16708-16717.

42 Yang F, Huo XS, Yuan SX, et al. Repression of the long noncoding RNA-LET by histone deacetylase 3 contributes to hypoxia-mediated metastasis. Mol Cell 2013;49:1083-1096.

43 Cayre A, Rossignol F, Clottes E, et al. aHIF but not HIF-1 alpha transcript is a poor prognostic marker in human breast cancer. Breast Cancer Res 2003;5: R223-R230.

44 Kuwano Y, Pullmann R Jr., Marasa BS, et al. NF90 selectively represses the translation of target mRNAs bearing an AU-rich signature motif. Nucleic Acids Res 2010;38:225-238. 
45 Jackson AL, Zhou B, Kim WY. HIF, hypoxia and the role of angiogenesis in non-small cell lung cancer. Expert Opin Ther Targets 2010;14:1047-1057.

46 Chua HL, Bhat-Nakshatri P, Clare SE, et al. NF-kappaB represses E-cadherin expression and enhances epithelial to mesenchymal transition of mammary epithelial cells: potential involvement of ZEB-1 and ZEB-2. Oncogene 2007;26:711-724.

47 Jiang YG, Luo Y, He DL, et al. Role of Wnt/betacatenin signaling pathway in epithelial-mesenchymal transition of human prostate cancer induced by hypoxia-inducible factor-1alpha. Int J Urol 2007;14: 1034-1039.

$48 \mathrm{Li} \mathrm{Y}$, Hively WP, Varmus HE. Use of MMTV-Wnt-1 transgenic mice for studying the genetic basis of breast cancer. Oncogene 2000;19:1002-1009.

49 Ying L, Chen Q, Wang Y, et al. Upregulated MALAT-1 contributes to bladder cancer cell migration by inducing epithelial-to-mesenchymal transition. Mol Biosyst 2012;82289-82294.

50 Ayesh S, Matouk I, Schneider T, et al. Possible physiological role of H19 RNA. Mol Carcinog 2002; 35:63-74.

51 Adriaenssens E, Lottin S, Berteaux N, et al. Cross talk between mesenchyme and epithelium increases H19 gene expression during scattering and morphogenesis of epithelial cells. Exp Cell Res 2002;275: 215-229.

52 Fellig Y, Ariel I, Ohana P, et al. H19 expression in hepatic metastases from a range of human carcinomas. J Clin Pathol. 2005;58:1064-1068.

53 Luo M, Li Z, Wang W, et al. Long non-coding RNA H19 increases bladder cancer metastasis by associating with EZH2 and inhibiting E-cadherin expression. Cancer Lett 2013;333:213-221.

54 Ling H, Spizzo R, Atlasi Y, et al. CCAT2, a novel noncoding RNA mapping to 8q24, underlies metastatic progression and chromosomal instability in colon cancer. Genome Res 2013;23:1446-1461.

55 Mulholland DJ, Kobayashi N, Ruscetti M, et al. Ptenloss and RAS/MAPK activation cooperate to promote EMT and metastasis initiated from prostate cancer stem/progenitor cells. Cancer Res 2012;72: 1878-1889.

56 Caldas C, Kern SE. K-ras mutation and pancreatic adenocarcinoma. Int J Pancreatol 1995;18:1-6.

57 Kanda $\mathrm{M}$, Matthaei $\mathrm{H}$, Wu J, et al. Presence of somatic mutations in most early-stage pancreatic intraepithelial neoplasia. Gastroenterology 2012;142: 730-733.

58 Schubbert S, Shannon K, Bollag G. Hyperactive Ras in developmental disorders and cancer. Nat Rev Cancer 2007;7:295-308.

59 Calhoun ES, Jones JB, Ashfaq R, et al. BRAF and FBXW7 (CDC4, FBW7, AGO, SEL10) mutations in distinct subsets of pancreatic cancer: potential therapeutic targets. Am J Pathol 2003;163:1255-1260.

60 Macgregor-Das AM, Iacobuzio-Donahue CA. Molecular pathways in pancreatic carcinogenesis. J Surg Oncol 2013;107:8-14.

61 Nakaya HI, Amaral PP, Louro R, et al. Genome mapping and expression analyses of human intronic noncoding RNAs reveal tissue-specific patterns and enrichment in genes related to regulation of transcription. Genome Biol 2007;8:R43.

62 Reis EM, Ojopi EP, Alberto FL, et al. Large-scale transcriptome analyses reveal new genetic marker candidates of head, neck, and thyroid cancer. Cancer Res 2005;65:1693-1699.

63 Brito GC, Fachel AA, Vettore AL, et al. Identification of protein-coding and intronic noncoding RNAs down-regulated in clear cell renal carcinoma. Mol Carcinog 2008;47:757-767.

64 Tahira AC, Kubrusly MS, Faria MF, et al. Long noncoding intronic RNAs are differentially expressed in primary and metastatic pancreatic cancer. Mol Cancer 2011;10:141.

65 Zhao Y, Shen S, Guo J, et al. Mitogen-activated protein kinases and chemoresistance in pancreatic cancer cells. J Surg Res 2006;136:325-335.

$66 \mathrm{Wu} \mathrm{X}$, Weng L, Li X, et al. Identification of a 4-microRNA Signature for clear cell renal cell carcinoma metastasis and prognosis. PLoS One 2012;7: e35661.

67 Weinberg RA. Leaving home early: reexamination of the canonical models of tumor progression. Cancer Cell 2008;14:283-284.

68 Caroline C, Murray GI. Current and emerging concepts in tumour metastasis. J Pathol 2010;222:1-15.

$69 \mathrm{Qi} \mathrm{P}, \mathrm{Xu} \mathrm{MD}, \mathrm{Ni} \mathrm{SJ}$, et al. Low expression of LOC285194 is associated with poor prognosis in colorectal cancer. J Transl Med 2013;11:122.

70 Chen FJ, Sun M, Li SQ, et al. Upregulation of the long non-coding RNA HOTAIR promotes esophageal squamous cell carcinoma metastasis and poor prognosis. Mol Carcinog. 2013;52:908-915.

71 Nie Y, Liu X, Qu S, et al. Long non-coding RNA HOTAIR is an independent prognostic marker for nasopharyngeal carcinoma progression and survival. Cancer Sci 2013;104:458-464.

72 Endo H, Shiroki T, Nakagawa T, et al. Enhanced expression of long non-coding RNA HOTAIR is associated with the development of gastric cancer. PLoS One 2013;8:e77070.

73 Tang L, Zhang W, Su B, et al. Long non-coding RNA HOTAIR is associated with motility, invasion, and metastatic potential of metastatic melanoma. Biomed Res Int 2013;2013:251098.

74 Wheeler TM, Leger AJ, Pandey SK, et al. Targeting nuclear RNA for in vivo correction of myotonic dystrophy. Nature 2012;488111-488115.

75 Ren S, Liu Y, Xu W, et al. Long noncoding RNA MALAT-1 is a new potential therapeutic target for castration resistant prostate cancer. J Urol 2013;190: 2278-2287.

$76 \mathrm{Xu} \mathrm{C}$, Yang M, Tian J, et al. MALAT-1: a long noncoding RNA and its important 3' end functional motif in colorectal cancer metastasis. Int J Oncol 2011;39: 169-175.

77 Park SM, Park SJ, Kim HJ, et al. A known expressed sequence tag, BM742401, is a potent lincRNA inhibiting cancer metastasis. Exp Mol Med 2013; 45:e31.

78 Qi P, Xu MD, Ni SJ, et al. Down-regulation of ncRAN, a long non-coding RNA, contributes to colorectal cancer cell migration and invasion and predicts poor overall survival for colorectal cancer patients. Mol Carcinog 2014 (e-pub ahead of print).

79 Bonnomet A, Brysse A, Tachsidis A, et al. Epithelialto-mesenchymal transitions and circulating tumor cells. J Mammary Gland Biol Neoplasia 2010;15: 261-273.

$80 \mathrm{Xu} \mathrm{ZY,} \mathrm{Yu} \mathrm{QM,} \mathrm{Du} \mathrm{YA,} \mathrm{et} \mathrm{al.} \mathrm{Knockdown} \mathrm{of} \mathrm{long}$ non-coding RNA HOTAIR suppresses tumor invasion 
and reverses epithelial-mesenchymal transition in gastric cancer. Int J Biol Sci 2013;9:587-597.

81 Kotake Y, Nakagawa T, Kitagawa K, et al. Long noncoding RNA ANRIL is required for the PRC2 recruitment to and silencing of p15(INK4B) tumor suppressor gene. Oncogene 2011;30:1956-1962.

82 Yap KL, Li S, Muñoz-Cabello AM, et al. Molecular interplay of the noncoding RNA ANRIL and methylated histone $\mathrm{H} 3$ lysine 27 by polycomb CBX7 in transcriptional silencing of INK4a. Mol Cell 2010;38: 662-674.

83 Nguyen VT, Kiss T, Michels AA, et al. 7SK small nuclear RNA binds to and inhibits the activity of CDK9/cyclin T complexes. Nature 2001;414: 322-325.

84 Eilebrecht S, Brysbaert G, Wegert T, et al. 7SK small nuclear RNA directly affects HMGA1 function in transcription regulation. Nucleic Acids Res 2011;39: 2057-2072.

85 Mourtada-Maarabouni M, Pickard MR, Hedge VL, et al. GAS5, a non-protein-coding RNA, controls apoptosis and is downregulated in breast cancer. Oncogene 2009;28:195-208.

86 Azzalin CM, Reichenbach $\mathrm{P}$, Khoriauli L, et al. Telomeric repeat containing RNA and RNA surveillance factors at mammalian chromosome ends. Science 2007;318:798-801.

87 Ng LJ, Cropley JE, Pickett HA, et al. Telomerase activity is associated with an increase in DNA methylation at the proximal subtelomere and a reduction in telomeric transcription. Nucleic Acids Res 2009;37:1152-1159.

88 Uchida T, Rossignol F, Matthay MA, et al. Prolonged hypoxia differentially regulates hypoxia-inducible factor (HIF)-1alpha and HIF-2alpha expression in lung epithelial cells: implication of natural antisense HIF-1alpha. J Biol Chem 2004;279:14871-14878.

89 Madamanchi NR, Hu ZY, Li F, et al. A noncoding RNA regulates human protease-activated receptor-1 gene during embryogenesis. Biochim Biophys Acta 2002;1576:237-245.

$90 \mathrm{Fu}$ X, Ravindranath L, Tran N, et al. Regulation of apoptosis by a prostate-specific and prostate cancerassociated noncoding gene, PCGEM1. DNA Cell Biol 2006;25:135-141.
91 Petrovics G, Zhang W, Makarem M, et al. Elevated expression of PCGEM1, a prostate-specific gene with cell growth-promoting function, is associated with high-risk prostate cancer patients. Oncogene 2004;23:605-611.

92 Tsang WP, Wong TW, Cheung AH, et al. Induction of drug resistance and transformation in human cancer cells by the noncoding RNA CUDR. RNA 2007;13: 890-898.

93 Qiu $\mathrm{M}, \mathrm{Xu} \mathrm{Y}$, Yang $\mathrm{X}$, et al. CCAT2 is a lung adenocarcinoma-specific long non-coding RNA and promotes invasion of non-small cell lung cancer. Tumour Biol 2014 (e-pub ahead of print).

94 Han L, Kong R, Yin DD, et al. Low expression of long noncoding RNA GAS6-AS1 predicts a poor prognosis in patients with NSCLC. Med Oncol 2013;30:694.

95 Zhao Y, Guo Q, Chen J, et al. Role of long non-coding RNA HULC in cell proliferation, apoptosis and tumor metastasis of gastric cancer: a clinical and in vitro investigation. Oncol Rep 2014;31:358-364.

96 Sun W, Wu Y, Yu X, et al. Decreased expression of long noncoding RNA AC096655.1-002 in gastric cancer and its clinical significance. Tumour Biol. 2013;34:2697-2701.

97 Matouk IJ, Abbasi I, Hochberg A, et al. Highly upregulated in liver cancer noncoding RNA is overexpressed in hepatic colorectal metastasis. Eur J Gastroenterol Hepatol 2009;21:688-692.

98 Huang JF, Guo YJ, Zhao CX, et al. Hepatitis B virus X protein (HBx)-related long noncoding RNA (lncRNA) downregulated expression by $\mathrm{HBx}$ (Dreh) inhibits hepatocellular carcinoma metastasis by targeting the intermediate filament protein vimentin. Hepatology 2013;57:1882-1892.

99 Wang CM, Wu QQ, Li SQ, et al. Upregulation of the long non-coding RNA PlncRNA-1 promotes esophageal squamous carcinoma cell proliferation and correlates with advanced clinical stage. Dig Dis Sci. 2014;59:591-597.

$100 \mathrm{He}$ W, Cai Q, Sun F, et al. linc-UBC1 physically associates with polycomb repressive complex 2 (PRC2) and acts as a negative prognostic factor for lymph node metastasis and survival in bladder cancer. Biochim Biophys Acta 2013;1832:1528-1537. 